\title{
Commentary \\ Developing Socio-Techno-Economic-Political (STEP) Solutions for Addressing Resource Nexus Hotspots
}

\author{
Bassel Daher ${ }^{1,2}$ (D), Rabi H. Mohtar ${ }^{1,3,4, *}$, Efstratios N. Pistikopoulos ${ }^{5}$, Kent E. Portney ${ }^{6}$, \\ Ronald Kaiser $^{2}$ and Walid Saad ${ }^{7}$ \\ 1 Department of Biological and Agricultural Engineering, Texas A\&M University, \\ College Station, TX 77843, USA; bdaher@tamu.edu \\ 2 Water Management and Hydrologic Sciences Program, Texas A\&M University, \\ College Station, TX 77843, USA; rkaiser@tamu.edu \\ 3 Department of Civil Engineering, Texas A\&M University, College Station, TX 77843, USA \\ 4 Faculty of Agriculture and Food Sciences, American University of Beirut, Beirut 1107 2020, Lebanon \\ 5 Texas A\&M Energy Institute, Texas A\&M University, College Station, TX 77843, USA; stratos@tamu.edu \\ 6 The Bush School of Government and Public Service, Texas A\&M University, College Station, TX 77843, USA; \\ kportney@tamu.edu \\ 7 The Bradley Department of Electrical \& Computer Engineering, Virginia Tech, Blacksburg, VA 24061, USA; \\ walids@vt.edu \\ * Correspond: mohtar@tamu.edu
}

Received: 4 December 2017; Accepted: 12 February 2018; Published: 14 February 2018

\begin{abstract}
The challenge of meeting increasing water, energy, and food needs is linked not only to growing demands globally, but also to the growing interdependency between these interconnected resource systems. Pressures on these systems will emerge to become hotspots with different characteristics, and will require a fresh look at the challenges existing both within each of the resource systems and at their respective interfaces. Proposing solutions to address different resource hotspots must be multi-faceted and need to acknowledge the multiple dimensions of the biophysical water, energy, and food systems, and the players connected with them. This commentary first explores the multiple dimensions of water, energy, and food systems as these relate to government, business, and society. It then identifies contemporary critical questions at the interface of these stressed resource systems. A 3-Filter framework is then introduced for vetting the feasibility of proposed resource allocation scenarios and to account for the bio-physical resource interactions and trade-offs, the stakeholder interactions and trade-offs, and to address governance and financing schemes for carrying forward the implementation of those scenarios.
\end{abstract}

Keywords: water-energy-food nexus; resource hotspots; multi-dimensional resource systems; multi-dimensional players; multi-faceted solutions

\section{Introduction}

We live in a world of non-uniform resource distribution and uneven resource demands. This results globally, in the emergence of resource nexus hotspots each with distinct characteristics and gap projections. A "resource nexus hotspot", or more specifically, a "water-energy-food (WEF) nexus hotspot" could be considered as "a vulnerable sector or region at a defined scale, facing stresses in one or more of its resource systems due to resource allocation at odds with the interconnected nature of food, energy, and water resources" [1]. Given the tight interconnectedness between water, energy, and food resource systems, the proposed solutions and interventions for addressing these hotspots need to be holistic. Whether policy, technological, or social interventions are considered, these need to be localized and contextualized. In addition to the diversity of resource constraints and interlinkages 
across cases, the nature of stakeholders, the difference in their goals, value systems, decision making power, and the way in which they interact, changes from one hotspot to another. Furthermore, the implementation of proposed interventions, and the success of that implementation, are subject to their modes of governance and their interactions at multiple scales. In order to properly assess and evaluate alternatives and possible interventions that may reduce pressures in a particular hotspot, we need to also ensure the feasibility of those scenarios within the boundaries and interactions of the physical resource system constraints, and their compatibility and suitability with involved stakeholders and governance systems. The growing body of literature related to WEF nexus research [2] has evolved since 2011, in Bonn [3] and the World Economic Forum [4], up until today, where we see resource interconnectedness and trade-offs present in many global discussions, including in the agendas of climate change and sustainable development goals. Different conceptualizations and approaches have transpired as part of this growing movement of holistic water-energy-food resource systems thinking. Examples include some that are focused on modeling water, energy and food systems [5-7], others that have an additional focus on climate and land use systems [8,9], and multi-scale analysis of socio-ecological systems [10]. These are in addition to the adoption of a water-energy-food nexus approach to addressing food security and sustainable agriculture challenges by the Food and Agriculture Organization of the United Nations [11], the World Bank's [12] water-energy nexus modeling for energy planning, the water, food, energy, and ecosystems approach of the Global Water Partnership [13] and UNECE [14], as well as the United Nation University's water-soil-waste nexus framework [15]. Furthermore, there is a common push toward developing and evolving these models by focusing on resource efficiency, as well as resource productivity [16-18].

In light of the current, growing WEF nexus research activity on several thematic and geographic fronts, this commentary highlights the multidimensionality of resource systems and the multifaceted nature of stakeholders; it outlines ways in which these multidimensional players and resource systems interact across scales. The resulting challenges for governance and policy coherence are elaborated and discussed. This paper will specifically: (1) explore the multiple dimensions of water, energy, and food systems, as these relate to government, business, and society; (2) identify contemporary critical questions and interlinkages across resource systems; (3) present a 3-Filter framework for vetting the feasibility of proposed resource allocation scenarios, through accounting for physical resource interactions and trade-offs, stakeholder interactions and trade-offs, and addressing governance and financing schemes for carrying forward the implementation of those scenarios.

\section{Resource Systems: Not Just Interconnected, but Also Multidimensional}

Drawing from systems theory, which describes a system as an organized entity (natural or manmade), made up of interrelated and interdependent parts, this commentary describes water, energy, and food as a system of interconnected resource systems.

\subsection{Water Coordinates: From $W\left(m^{3}\right)$ to $W\left(m^{3}, X: Y\right.$, Time, Source, Quality)}

Discussions of projected water gaps across different regions are common in the literature. These projected water gaps often illustrate the difference between projections of water supply and demand. Addressing such gaps usually focuses primarily on identifying new alternative sources of water to boost supply, while also reducing demand within different water consuming sectors. While the availability of specific volumes of water $\left(\mathrm{m}^{3}\right)$ is a critical determinant to our ability to produce food, cool energy-generating power plants, and provide water to our cities, it is not the only dimension to be considered (Figure 1): there is also a spatial dimension to water. The physical location of water is important: how far is it from its final use; is the future availability of one body of water more vulnerable to future climatic changes because of its location; is the same body of water subject to quality threats due to potential industrial leaks or intensified agricultural activity upstream; and, is it subject to future scarcity threats due to increased water demanded for economic activity upstream? There is a temporal dimension to water. Water availability varies with the time of the year: planning its allocation varies 
with the seasons. Climate change has an effect on rainfall patterns, causing intensification of rain events in shorter periods of time. Different sources and types of water come with different energy and carbon footprints. Is the water present at the surface, or part of a ground water aquifer? How much energy is required to treat, desalinate, pump or convey a needed amount of water to its final use? What is the impact on neighboring ecosystems? There are different qualities of water, which determine its suitability for different end uses: for example, water of certain levels of salinity might be suitable for salt resistant crops; urban waste water could be treated and allocated for different uses, including agriculture, landscaping, and others. Thus, allocating water $\left(\mathrm{m}^{3}\right)$ by considering only demand and supply of its volumes, misses the bigger picture and the larger implications on the resource systems connected to water. This allocation model unravels once we also consider water in relation to those additional "coordinates", $\mathrm{W}\left(\mathrm{m}^{3}, \mathrm{X}: \mathrm{Y}\right.$, Time, Source, Quality). The decisions made for the amount, time, location, source, and quality will, in turn, dictate the energy and carbon footprints, and the cost. Similarly, energy and food have multiple dimensions.
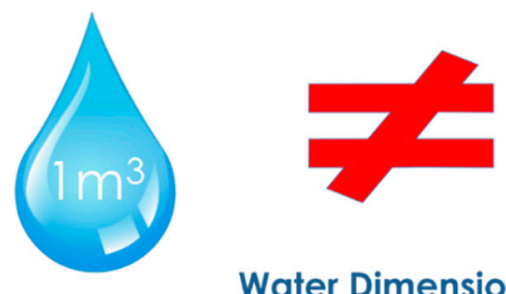

Water Dimensions
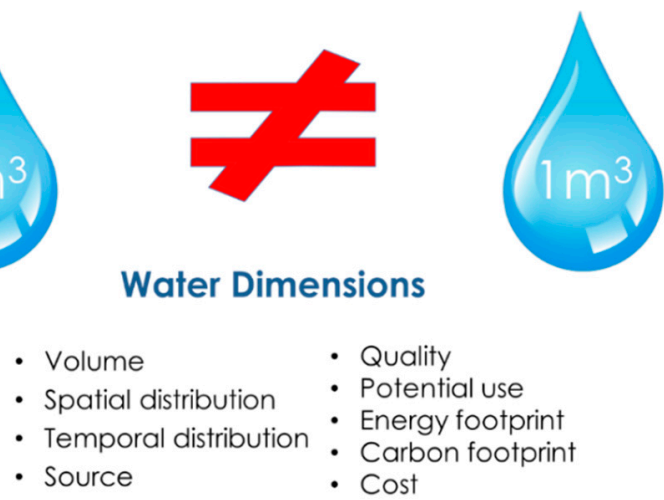

Figure 1. The multiple dimensions of water.

\subsection{Food Coordinates: From F (Ton) to F (Tons, Source, X:Y, Time, Kcal)}

Meeting municipal or energy demands from agriculture (tons) dictates what types, and in what amounts, specific crops need to be grown or imported. The nature of the diet and the standard of economic well-being of a given nation or community plays a role in shaping these demands. For example, a nation or region with a growing middle class is likely to experience increasing demand for meat-based diets. It also is a function of energy policies, which might offer incentives or disincentives for using biofuels for energy generation. The source and way in which crops and food products are grown are a function of available technologies and farmers' capacities. The resources required for traditional open agriculture, green house agriculture, aquaponics, or hydroponics, all differ. The type of irrigation technology and fertilizer additive required to produce a given food product impacts energy consumption, carbon emission, and total production costs. Growing food also has a spatial component $(\mathrm{X}: \mathrm{Y})$ : food production depends on climate, soil quality and suitability, water availability, and other factors. It depends on proximity and access to markets and consumers. There is also a temporal dimension (X:Y) to food production: what time of the year (season) is best for certain crops; what specific crop rotations ensure the long-term soil health and future productivity; what are the more favorable seasons to grow given products in a way that lowers the requirements for water, fertilizer, and energy? Further, the dietary and nutritional requirements of the growing population impact the type of food products necessary for inclusion in the local food basket (Figure 2). 


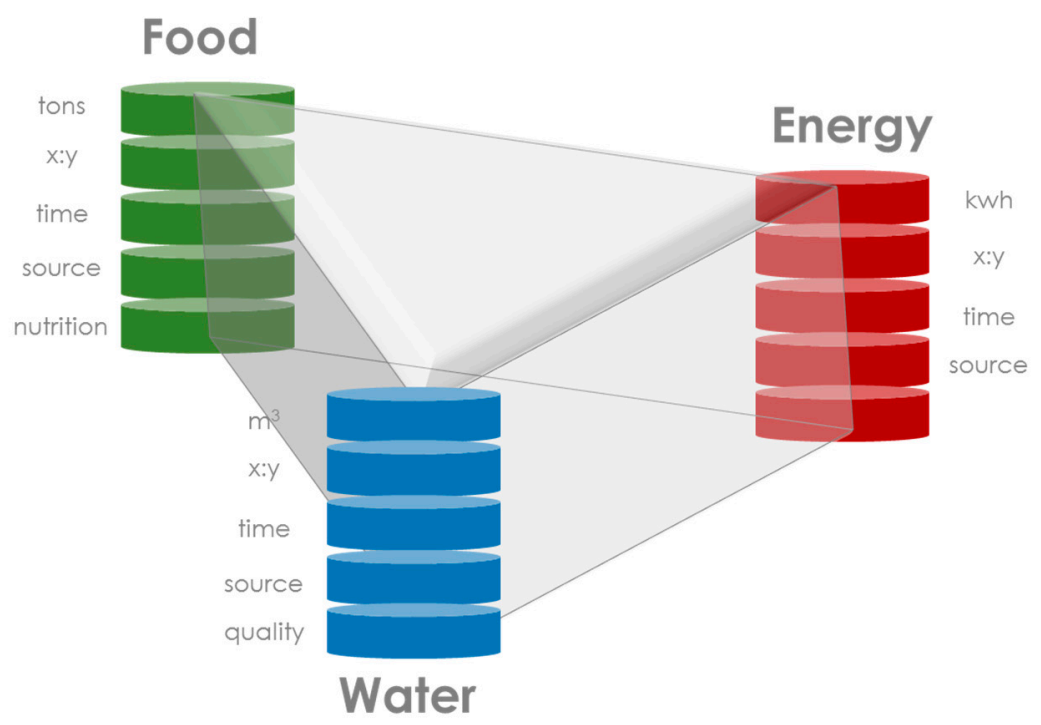

Figure 2. Resource systems and their interactions are multidimensional.

\subsection{Energy Coordinates: From $E(k W h)$ to $E$ ( $k W h$, Source, X:Y, Time)}

Energy (Kwh) is a critical input across different economic sectors: it is required for food production, treatment and conveyance of water, transportation, and powering cities, among others. The choice of an energy portfolio is dependent on locally available energy sources (conventional, non-conventional) and access to energy markets, each of which results in different impacts on water demands and quality, cost, emissions, etc. Energy has a strong spatial component (X:Y). A decision to invest in solar or wind energy, for example, is highly dependent on the suitability and potential yield of these energy sources in a given land area. A major and persistent challenge facing the energy system, particularly with regard to non-conventional sources, is energy storage. The mismatch between peak demand and peak production of some sources, solar for example, points to the risks in relying solely on such energy sources to meet demand (time).

A ton of rainfed wheat harvested and processed using diesel powered power plants is different from a ton of wheat grown in a drier region that relies on irrigation from ground water aquifers dependent on solar powered technologies through its production supply chain. This is one of many examples of how producing the same quantity of wheat might exert very different stresses on the interconnected resource systems. Similarly, a $\mathrm{kWh}$ of energy produced from natural gas, using a steam generator with a cooling technology that depends on neighboring surface water, differs from a $\mathrm{kWh}$ of energy produced by concentrated solar power (CSP), with a cooling tower that depends on groundwater. It is also worth noting the important role of trade and cooperation in alleviating the stresses facing these interconnected resource systems. These could be in the form of food imports and exports, virtual water trade through importing and exporting the water embedded in products, energy trade, technology and knowledge transfer. Diversifying an energy portfolio could consist of exploring different energy sources within a given country, for example, but it should also extend beyond that to assess the risks associated with producing that energy nationally, as opposed to importing it. The case with food production is similar.

\section{Critical Questions and Interlinkages}

Global population will continue to increase for the foreseeable future. The middle class is rapidly growing, especially in developing regions of the world. Global threats, including climate change, the increasing vulnerability of global financial systems, inequity of resource distribution, and growing resource scarcity, among others, make the assessment of resource allocation alternatives at different scales ever more critical. Asking the right critical questions at the interface of these stressed 
resource systems and accounting for their multi-dimensionality becomes instrumental in effectively addressing the allocation challenges as we move forward. Figure 3 illustrates the critical questions schematically. These questions are aimed at the main interlinkages and interfaces across the different resource systems. Municipalities and urban settings are areas within which most of our population growth is concentrated. This makes these areas a source of increased pressures on resources, yet with a potential to contribute towards reducing them as well. For this reason, questions relating to the interaction between the water, energy, and food resource systems within these areas have been included. Our ability to model these questions, while holistically accounting for the influences and trade-offs associated with decisions made within various sectors, is a precursor to identifying synergistic interventions that reduce the extent of their interdependencies.

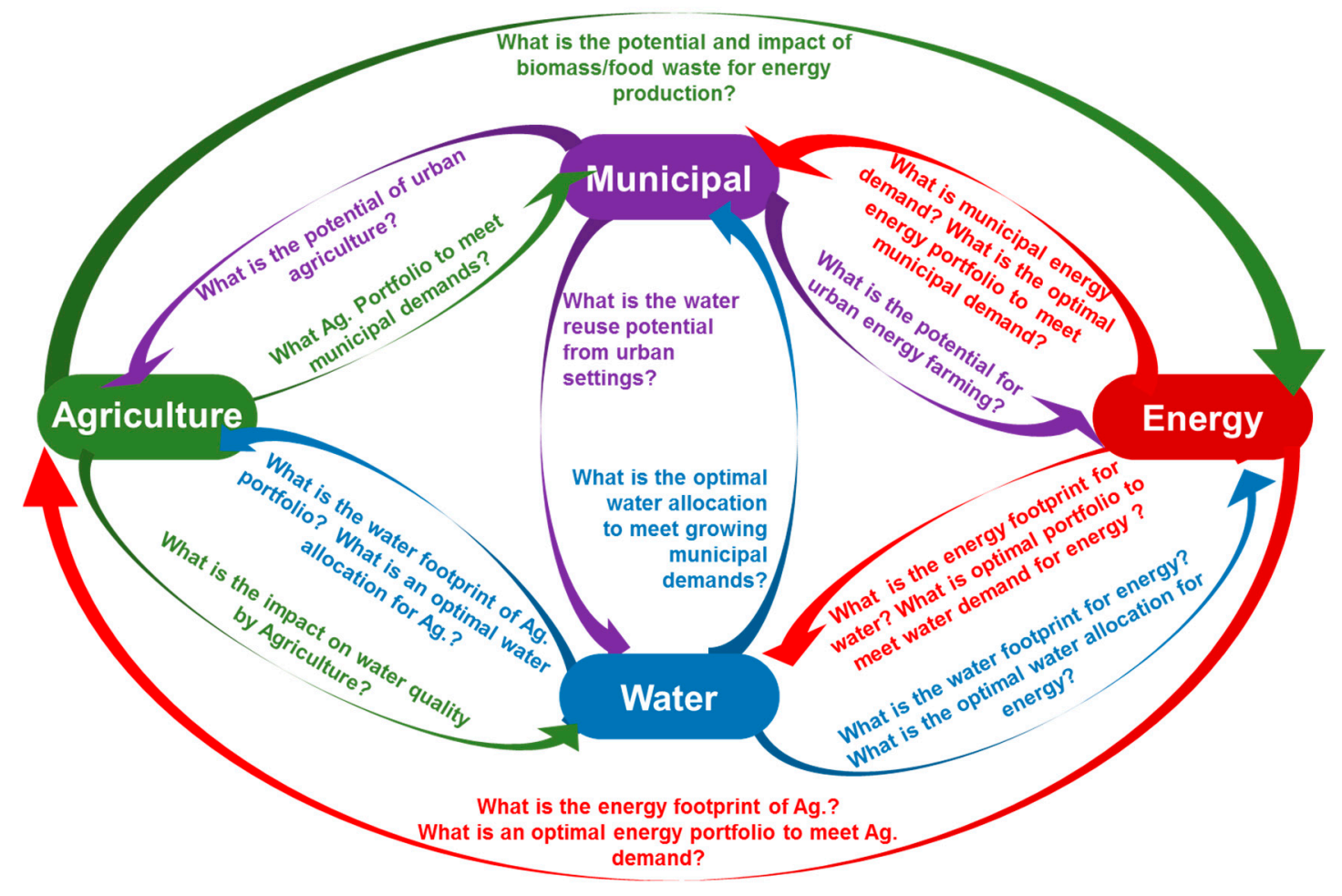

Figure 3. Overarching critical questions across resource systems.

Stresses resulting from the availability and quality of water are affected by decisions made within the different systems: what crops to grow and when; what choices of energy should constitute an energy portfolio; how are urban areas projected to expand? Given the various dimensions of water, the main question becomes one that explores water allocation scenarios to reduce competition between resource systems and reduce stress within the water system itself, while ensuring that environmental flows and quality limits are not exceeded. Similarly, demand for energy is driven by decisions and projections made within water, agricultural, and urban centers. The choice of different energy portfolios directly impacts requirements for water, land, and financial resources, as well as carbon emissions. Decisions made within those same resource systems could have a role in releasing stresses facing the energy system through the use of water to generate hydropower, biomass to produce energy, and utilization of urban areas to harness solar energy at the household level. A holistic assessment and quantification of these energy portfolios will contribute to identifying the trade-offs between the alternative pathways moving forward. There is also a need to assess different scenarios for agriculture and food production (water, energy, land, emissions, and financial needs) in light of the different variables and responses to the demands of a growing population. In addition to viewing and modeling urban areas as "resource sinks", the potential for growing cities to become larger resource producers 
could play a role in alleviating pressures on resource systems. Related questions need to be captured to effectively model the impact of specific interventions, future scenarios, and the impacts of these on this system of systems: what is the water reuse potential from urban settings; what is the potential of harvesting solar energy from rooftops and how much would it cost and who will pay for it? What infrastructure would be needed? What is the potential of urban agriculture; could it reduce some of the stresses that face the agricultural system? How might urban agricultural centers increase the resilience and food security of city residents? Is current city infrastructure able to support it?

More integrative modeling of these interconnections is needed to assess and evaluate future interventions and scenarios: it is necessary to capitalize on existing tools and to modify and develop others where needed. Several tools are available in the literature that explore aspects of these questions. For example, the Catchment Water Allocation Tool by IWMI [19] allows assessment of different interventions that support integrated irrigation and aquaculture in watersheds. Similarly, SEI's [20] water evaluation and planning system (WEAP) supports the allocation of water between agricultural, municipal, and environmental use. Both LEAP (long range alternatives planning system) [21] and WEAP analyze the interactions between water and energy uses. CROPWAT by FAO [22] assists in calculating water requirements and irrigation needs for crops based on soil climate and crop data. Many other tools exist that could be used to answer some of the questions addressed above including, CLEWS [23], MuSIASEM [24], and the WEF Nexus Tool [6,25]. More tools can be found in FAO [26] and IRENA [27]. However, moving forward, one of the main challenges of such tools within an integrative platform is the incompatibility of inputs and outputs, the differing scales, and establishing uniformity in assessment criteria across tools.

\section{Players Are Interconnected and Multi-Dimensional}

In addition to the complexity of the multidimensional physical resource interconnections, one must also deal with the reality that these common resources are consumed, regulated, and impacted by different stakeholders and decision makers (Figure 4). The concept of "tragedy of the commons" was first introduced by Hardin [28], who described the "commons" as any shared and unregulated resource. According to the "collective action problem", people acting independently will result in a worse outcome than if they coordinate. Individuals will work towards maximizing their own utility, making everyone, including themselves, worse off compared to when they act cooperatively [29]. Ostrom [30], one of Hardin's critics argued that humans are more complex than he assumed and that resources can be managed through local contextualized governance solutions to local problems within local communities, thus avoiding the "tragedy" [31]. Her studies showed examples of how local communities successfully managed common resource pools, including forests and fisheries. Further research in recent years focused on the importance of understanding the interactions between natural and human systems [32-36]. Ostrom [37] introduced a multi-tier framework for analyzing interactions among linked social-ecological systems. Madrid et al. [38] applied concepts to the social-ecological system to develop a multi-scale integrated assessment of interactions between ecosystems and societal "metabolisms".

This commentary builds on a wide body of literature that focuses on the interactions between government, business, and society; and it categorizes these players into three types, accordingly [39-44]. The commentary highlights the way in which a better understanding of those interactions can be useful in the context of addressing resource hotspots. The following section explores those dynamics. We acknowledge that this representation is a simplification of complex categories of players and interactions which this commentary will not expand on.

The three types of players are driven by different goals as they interact with each other. "Society", includes among others, the general public, NGOs, youth organizations, academia, families, religious groups, individuals, unions, and online communities. Players within "society" make decisions regarding the consumer products they utilize, and where they come from. In democratic societies, 
individual members of this group have the right to vote and to protest against what they perceive to be unjust or inequitable laws and regulations, which may also occur informally in others.

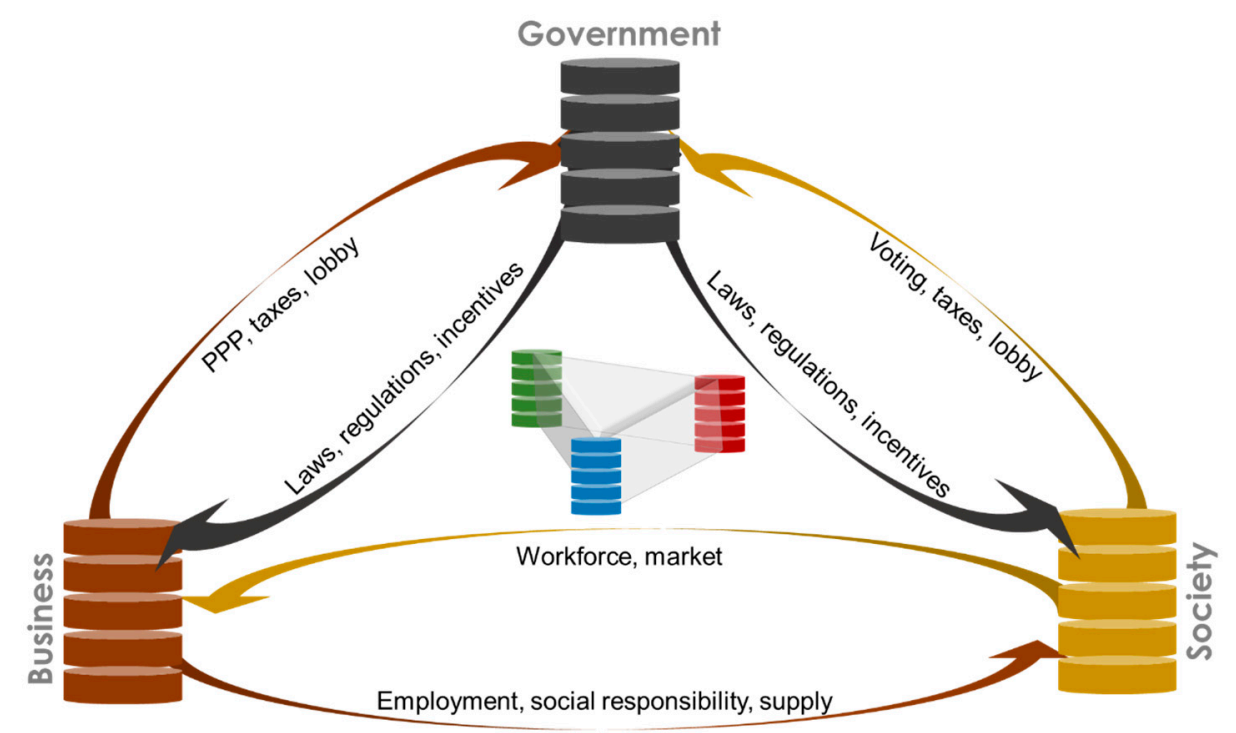

Figure 4. Multidimensional resource systems and players and their interconnections.

"Businesses" are profit or 'value' generating bodies that respond to society's demands for goods and services. Businesses are also entities that provide employment in society: an intimate demand-supply relation exists between the two. Different types of businesses exist across sectors: the ability to make a change, whether through improving technological efficiencies in the supply chain or through their role in social/corporate responsibility, directly impacts the different resource systems and their future allocations. Businesses have an increasing stake in being better stewards of resources, perhaps water, which is a result of encountered disruptions due to water supply challenges [45]. "Government" is a series of constructs and processes that make laws and regulations, represented (in democratic societies) by legislative, judicial, and executive branches. Depending on the scale considered, government includes ministries, river water authorities, ground water districts, local governments, and city councils, among others. The way in which water, energy, and food are governed may vary at different scales, from centralized to decentralized or other, hybrid, forms of governance. Players within "government" interface and interact with players from "business". Public-private partnerships are increasingly popular for financing long term infrastructural projects, such as support for particular research aimed at improving a technology in which the private sector provides financial support and the government sector provides facilities (such as National Labs in the USA). Government players, at a specific scale, have the ability to incentivize the use of specific technologies, thereby impacting the "promoted" businesses. They interact with and are dependent upon one another. Further, government investment in infrastructure that facilitates transportation is good for businesses: it facilitates supply chains. Governmental players also have a role in incentivizing specific consumption behaviors within society and for businesses, which may be effected through subsidies. Government players, especially those in elected positions, want to ensure they maintain public support to remain in power, which also factors into their decisions.

\section{Resource Systems and Players Differ and Interact within and across Scales}

Government, business, and societal players across the water, energy, and food systems have differing goals, value systems, and decision-making powers, at differing scales. Decisions made by one within a specific resource system and at a specific scale, could have implications for another within a different resource system or scale. Such interactions are potentially complex, for example, a decision 
made to subsidize electricity or the installation of solar pumping stations for farmers at the national scale, might incentivize those farmers to pump more water in order to increase their food production. While this would create positive economic impact for farmers, and a carbon benefit when compared to diesel pumping, it might also result in increased risk of groundwater depletion or degradation at the municipal scale (Figure 5).

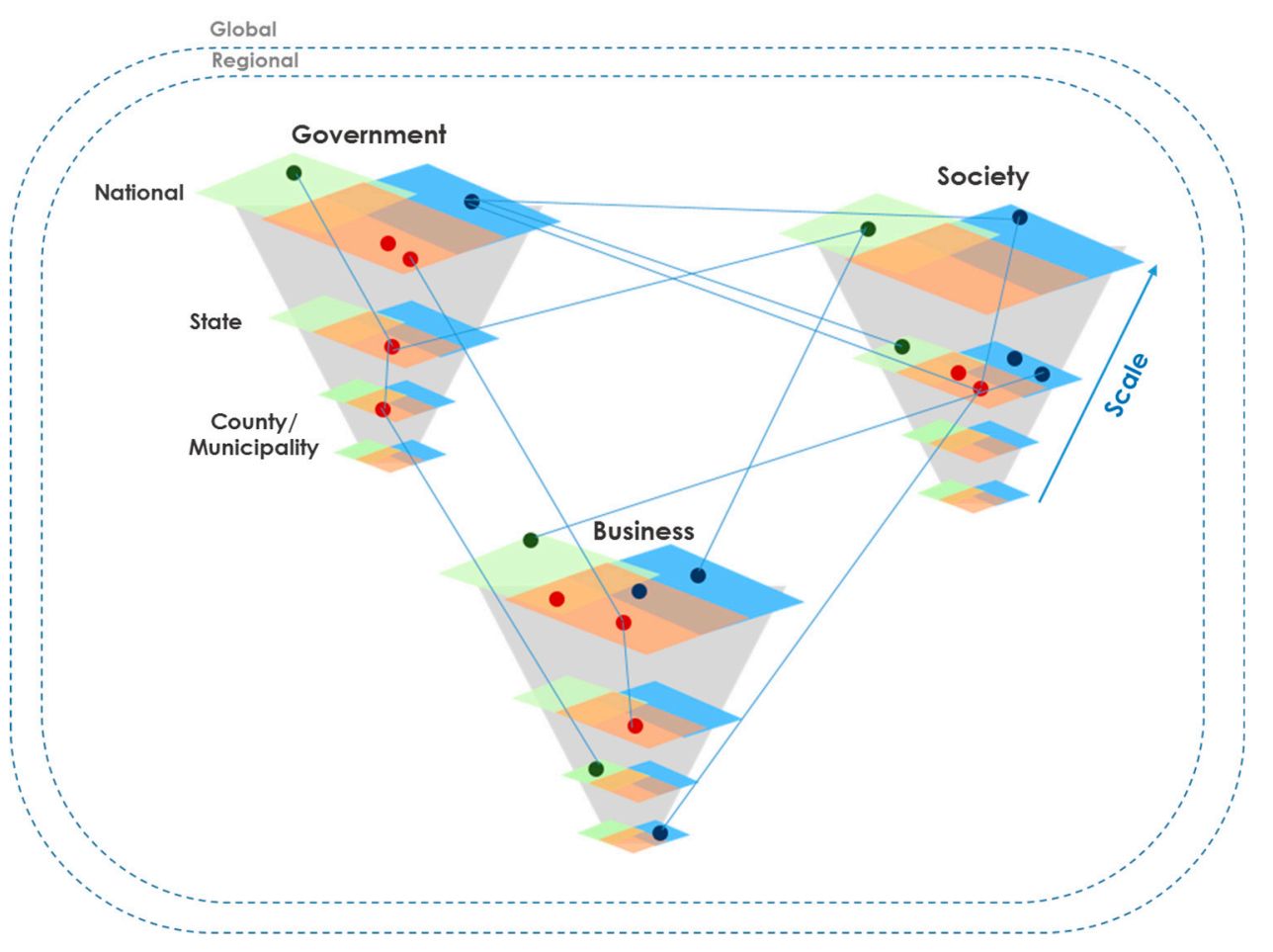

Figure 5. Interaction between different players across scales.

Another challenge is policy incoherence across scales: while those same farmers receive electricity subsidies from the federal government to encourage increased production, they might also be faced by groundwater laws at the basin scale that limit water pumping.

In light of our growing understanding and knowledge of the extent to which physical resource systems are interconnected, there is a need for a better understanding of how decisions and players interact and share risks [46] across scales: this points to the need for better identification of synergies between different decisions, and for avoiding the potential competition that might result from incoherent policies. Policies created to incentivize a specific action at a specific scale could conflict or compete with other actions at different scales. Specifically, there is a need for developing mechanisms for quantifying policy coherence through quantifying the impact of proposed policies across different sectors, within the same scale, and across scales. There is also a need to identify the compatibility of "current institutional setup" and "cross-sectoral interaction" with the nature of physical resource systems and their interconnections.

\section{An Iterative 3-Filter STEP Framework for Vetting WEF Nexus Scenarios}

There are risks associated with planning and managing resource systems within silos. Solutions for such complex, interconnected, and uncertain problems cannot be only technical; they cannot account only for physical resource constraints, or offer only socio-economic, technological, political, or financial interventions. Proposed scenarios must be multi-faceted, and represent a complete package including an understanding of the resource systems, their interactions, and the biophysical and economic trade-offs between different projected pathways forward. Scenarios must be vetted with consideration 
of the nature of different stakeholders, their interactions, and the trade-offs that become apparent during dialogue, in negotiation, and through conflict. Once the bio-physical resource and stakeholder landscapes are understood, several potentially feasible scenarios are likely to emerge: these need proper governance structures and financing schemes to be realized and sustained. Thus, we can arrive at a STEP nexus solution: a proposed scenario vetted from socio-techno-economic-political (STEP) perspectives. Different suites of tools, models, and instruments are available to support researchers across disciplines in prescribing contextualized, holistic, STEP nexus solutions for a given resource challenges or nexus hotspots. Figure 6 presents a 3-Filter framework. The presented framework is intended to offer analysts, modelers, "nexus tool" developers, engineers, and social and policy researchers working towards addressing resource nexus hotspots-while each focus separately on vetting different aspects of proposed scenarios-a conceptual guideline with a suggested structured stepwise approach, and iterative feedback cycles, to guide their collaboration as they work towards arriving at STEP nexus solutions.

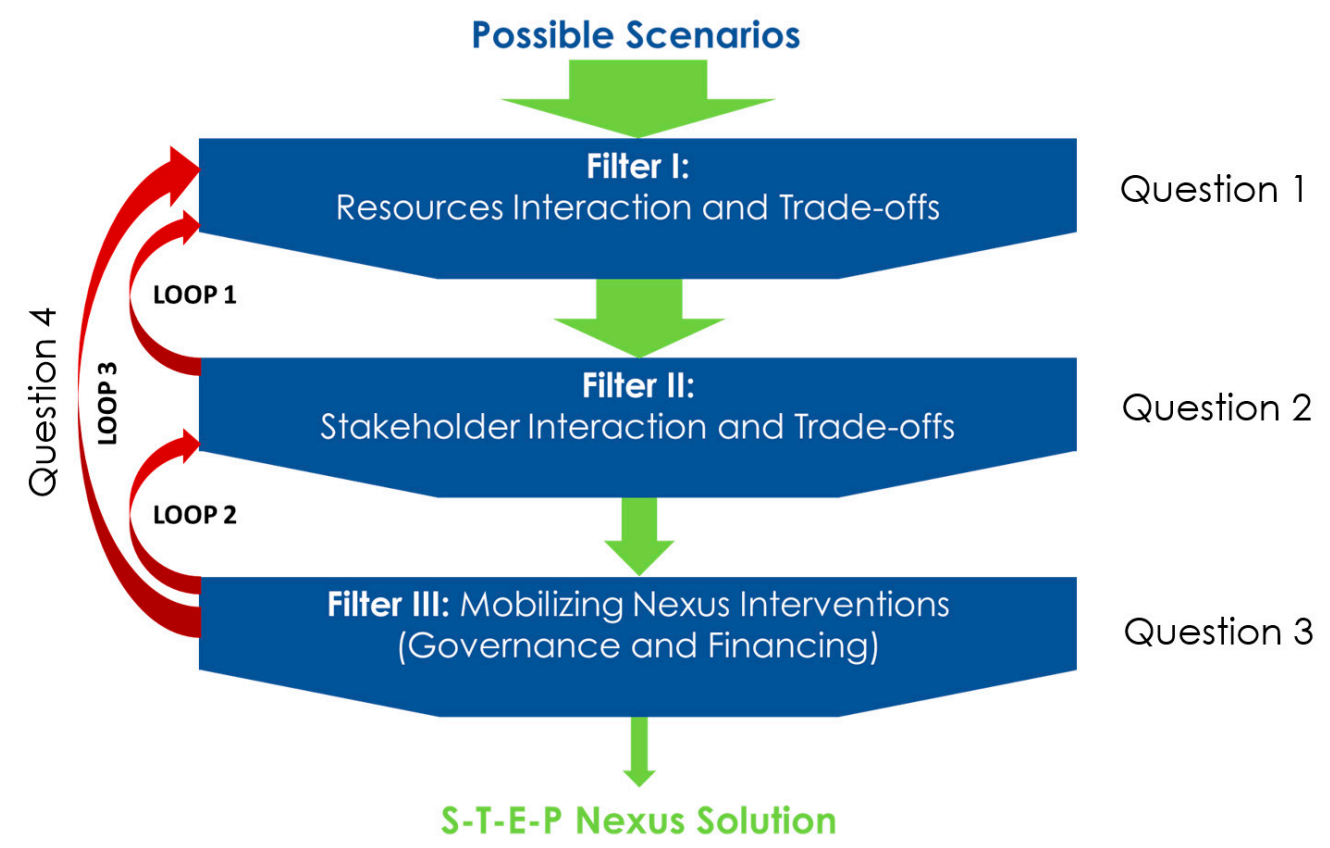

Figure 6. Iterative socio-techno-economic-political (STEP) nexus solution guiding framework.

This framework requires that all three "filters" be checked before a proposed scenario is prescribed as a nexus solution that addresses a specific critical question. It is worth mentioning here that the goal of the outlined questions, or suite of questions, is to act as a guide towards the choice of different tools, models, and instruments to help holistically vet a proposed scenario. The answers to those questions might not be a clear Yes or No. That will depend on the availability of needed data, reliability of the used tools, as well as the nature of the critical question being addressed. In order to briefly demonstrate the framework, we will refer to the earlier example of proposing a future energy portfolio scenario at a national scale.

\section{Feedback Loops and Cross-Thematic Interactions}

a. Filter I: Resources interaction and trade-offs

Question \#1: Are the proposed resource allocation scenarios moving forward within the physical resource constraints at the given operational scale? Is there sufficient water, land, financial, and human capital resources for the given scenario? 
If YES: Move to Filter II.

If NO: Develop new scenarios that do not require resources that exceed available limits.

Specific to our example on identifying a future energy portfolio, we need to assess the resource needs (water, land, financial, environmental, and others) associated with business-as-usual, as opposed to those needed for different proposed portfolios. How much more, or less, water and land would be needed if reliance on solar energy is increased by $20 \%$, for example? Which solar energy technology is most suitable? How do the resources needed for this shift affect and compete with resources needed for agriculture? Will we have competition with agriculture over the same available land, or is the land suitable for solar energy but not arable? Providing a quantification to answer these questions is facilitated by using, or customizing, existing integrative resource assessment tools from the literature. That quantification needs to be done while capturing the interconnections between the multi-dimensional system of systems (Section 2). The choice of tools would depend on the critical question in hand.

b. Filter II: Stakeholder interaction and trade-offs

Question \#2: Given the nature of the involved stakeholders, their interactions, power relations, value systems, and goals, which of the scenarios identified as 'feasible' in Question 1 could be implemented? Are there challenges beyond physical resource constraints that relate to understanding the realities of the stakeholder landscape?

If NO: Move to Filter III to check governance structures and financing schemes for scenario.

If YES: Return to Filter I (Loop 1) to explore different scenario possibilities.

In this filter, we need to identify who are the stakeholders (governmental, business, and societal) connected with a decision to shift to an additional $20 \%$ solar energy. How well would households respond to government incentives for installing roof top solar panels? What role do conventional energy producers have in affecting such a decision? How encouraging are market entry conditions for new solar panel manufacturers to start operating? Are there any imposed barriers that might make the $20 \%$ goal an ambitious one to reach within a specified timeframe? How much do farmers have a say in making such a decision? What level of coordination and cooperation exists between energy and other water and agricultural planning institutions? To address these questions, we might need instruments like game theory, direct engagement with stakeholders through questionnaires, surveys, workshops, focus groups, and other participatory approaches to help with understanding these interactions and the feasibility of proposed scenarios (Section 4).

\section{c. Filter III: Governance and Financing}

Question \#3: If the scenario clears Loop 1, through Filters I and II, who would govern the implementation of the scenario moving forward, and who will finance it? Is this consistent with the stakeholder involvement and the interactions presented in Filter II? Does implementing the given scenario result in policy coherence? Does the existing governance structure allow for implementation?

If YES: Loop 2 clears, the proposed scenario could be promoted.

If NO: we have the option of investigating other scenarios identified as 'feasible' from both the physical resource and the stakeholder perspective, though Loop 2. Alternatively, we could go through Loop 3 and investigate other scenarios in Filter I.

Are there any budgetary limitations that would not allow a government to invest in solar farms, or provide subsidies for solar panels at a household level and within a given timeframe? Would implementation of the $20 \%$ goal be centrally led by the government or through a more decentralized approach? Will the company providing solar panels be government-owned? Would panels be sold at a predetermined price or will price be determined by a free market approach? Are there any policies at 
the local levels (municipal land zoning regulations for example) that might challenge a federal goal of switching to solar? (Section 5).

Question \#4: Does a proposed governance structure ensure that the scenario provided by Filter I can be implemented? Are there any limitations/constraints?

If YES: Loop 3 clears.

If NO: Revisit the solution portfolio in Filter I and propose another solution; one that fits Filter III limitations.

Finally, we must check whether any of the limitations that may have emerged from Filter III would challenge the implementation of the initially proposed scenario from a bio-physical and technical perspective. This would serve as a final cross-check before promoting a nexus solution.

Using the outlined guiding framework, a suggested scenario undergoes rigorous trial and error and checks to ensure that:

a. $\quad$ long term sustainability of the physical resource is not compromised (Filter I);

b. $\quad$ stakeholders are effective partners in the solution (Filter II);

c. implementation and long-term governance of the solution are feasible (Filter III).

\section{WEF Nexus, Government, Business, Society and Sustainable Development Goals (SDGs): Capitalizing on Existing Momentum}

In the coming 15 years, 193 United Nations member states are committed to work toward achieving a set of 17 sustainable development goals (SDGs) [47]. These goals include specific targets and local indicators for monitoring progress on water, energy, and food securities, and others related to economic growth, and sustainable consumption, among others. The water-energy-food nexus research community has a unique opportunity to leverage the momentum toward these goals. Figure 7 shows a preliminary mapping of some of these goals that are directly related to the interconnected resource systems, the players, and the interactions between them (Figure 4 with mapped SDGs). As nations work toward the 17 goals, they need to be aware of the extent of their interconnectedness and the potential competition among them [48]. In order to ensure arrival at these goals by 2030 and without unintended consequences, action plans must be developed with an understanding of the interconnections between the physical resource systems and the players involved with them. Achieving these goals requires innovative plans across different scales and could benefit from a framework that provides a structured approach for guiding collaboration across disciplines. As we continue to investigate and quantify the critical questions identified in Figure 3, through case studies at different scales and across a variety of eco-zones, political, market, and social environments, we are guided by the framework outlined in Figure 6. We will learn lessons that would result in revisiting and refining our approaches for addressing complex resource hotspots, thus enabling us to more effectively work toward achieving the Sustainable Development Goals. 


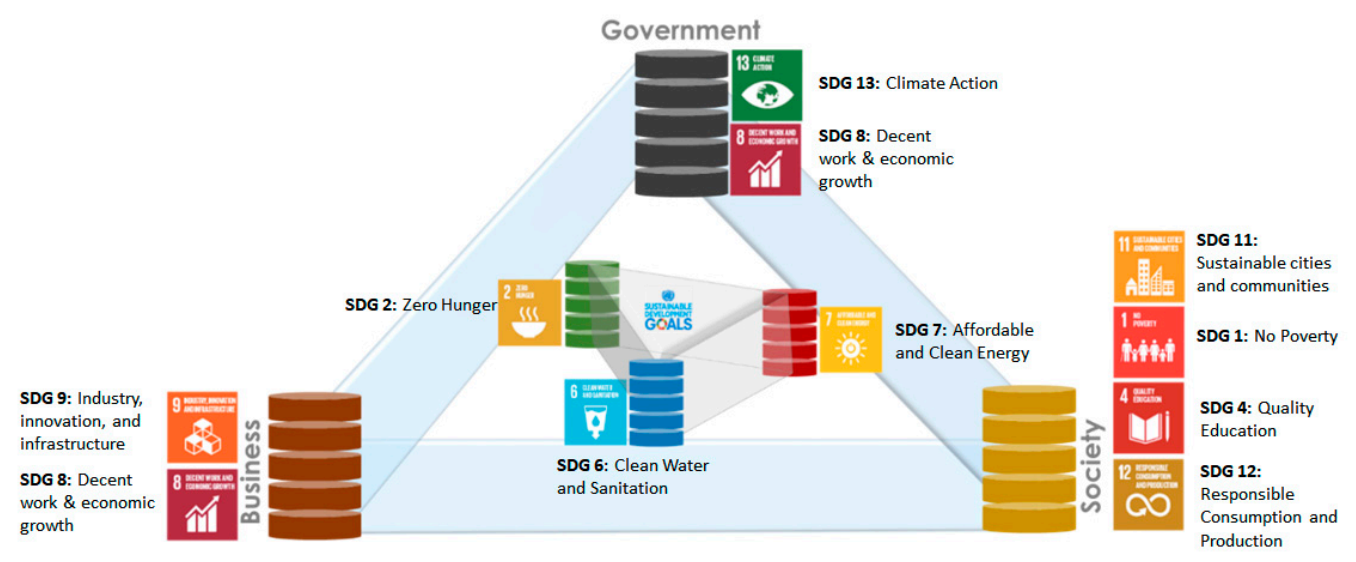

Figure 7. Role of water-energy-food (WEF) nexus and government-business-society interactions towards achieving sustainable development goals (SDGs).

\section{Concluding Remarks}

Moving forward, and as part of finding solutions for complex resource hotspots, several challenges exist that must be addressed. With regard to integrative resource assessment tools, there is a need for improving the compatibility of different tools that address critical questions guided by the interactions presented in the overarching WEF platform (Figure 3): this enables building on existing tools and avoiding duplication of effort. There is also a need for better quantification of the interactions between different players in order to identify implementable solutions. Given that players and resources systems interact across scales, there is a further need of better understanding and quantifying those interactions and ensuring solutions are implemented through policies that are coherent across scales. There is no one size tool that fits all for assessing physical resource interactions, stakeholder interactions, and policy and governance challenges. Therefore, localized and contextualized quantification and assessment is necessary. The 3-Filter STEP framework offers guidance through the different elements that need to be accounted for while assessing and promoting a nexus solution. Proposing feasible, implementable, sustainable solutions requires truly inclusive transdisciplinary conceptualization, quantification, and assessment of current and projected resource hotspots.

Acknowledgments: This research was funded in part by Texas A\&M University Water Energy Food Nexus Initiative and supported in part by the U.S. National Science Foundation under Grant OAC-1638283 and INFEWS Award No. 1739977.

Author Contributions: Bassel Daher and Rabi H. Mohtar conceived the original concept for the Commentary. Bassel Daher drafted the manuscript. Rabi H. Mohtar, Efstratios N. Pistikopoulos, Kent E. Portney, Ronald Kaiser and Walid Saad are responsible for the supervision of the Ph.D. research; they revised the manuscript critically for important intellectual content, providing suggestions and comments, each from their own area of expertise. All the authors read and approved the final manuscript.

Conflicts of Interest: The authors declare no conflict of interest.

\section{References}

1. Mohtar, R.H.; Daher, B. Water-Energy-Food Nexus Framework for Facilitating Multi-stakeholder Dialogue. Water Int. 2016, 655-661. [CrossRef]

2. The Water, Energy, and Food Security Resources Platform. Available online: https:/ / www.water-energyfood.org/start/ (accessed on 7 January 2018).

3. Bonn Conference. Understanding the Nexus. 2011. Available online: http://wef-conference.gwsp.org/ fileadmin/documents_news/understanding_the_nexus.pdf (accessed on 12 February 2018).

4. World Economic Forum. Water Security: The Water-Food-Energy-Climate Nexus: The World Economic Forum Water Initiative. 2011. Available online: http://www.springer.com/us/book/9781610910262\# aboutAuthors (accessed on 12 February 2018). 
5. Bazilian, M.; Rogner, H.; Howells, M.; Hermann, S.; Arent, D.; Gielen, D.; Steduto, P.; Mueller, A.; Komor, P.; Tol, R.S.J.; et al. Considering the energy, water and food nexus: Towards an integrated modelling approach. Energy Policy 2011, 39, 7896-7906. [CrossRef]

6. Daher, B.; Mohtar, R.H. Water-Energy-Food (WEF) Nexus Tool 2.0: Guiding integrative resource planning and decision-making. Water Int. 2015, 40, 748-771. [CrossRef]

7. WEF Nexus Research Group. Available online: https:/ / wefnexus.tamu.edu (accessed on 9 January 2018).

8. Howells, M.; Rogner, H. Water-energy nexus: Assessing integrated systems. Nat. Clim. Chang. 2014, 4, 246-247. [CrossRef]

9. Howells, M.; Hermann, S.; Welsch, M.; Bazilian, M.; Segerström, R.; Alfstad, T.; Gielen, D.; Rogner, H.; Fischer, G.; van Velthuizen, H.; et al. Integrated analysis of climate change, land-use, energy and water strategies. Nat. Clim. Chang. 2013, 3, 621-626. [CrossRef]

10. Giampietro, M.; Aspinall, R.J.; Ramos-Martin, J.; Bukkens, S.G.F. Resource Accounting for Sustainability Assessment: The Nexus Between Energy, Food, Water and Land Use; Routledge, Taylor \& Group: London, UK, 2015.

11. FAO. Walking the Nexus Talk: Assessing the Water-Energy-Food Nexus in the Context of the Sustainable Energy for All Initiative. 2014. Available online: http:/ / www.fao.org/3/a-i3959e.pdf (accessed on 12 February 2018).

12. World Bank Group. Modeling the Water-Energy Nexus: How Do Water Constraints Affect Energy Planning in South Africa? 2017. Available online: https://openknowledge.worldbank.org/handle/10986/26255 (accessed on 12 February 2018).

13. GWP. Water, Food, Energy, and Ecosystems. 2017. Available online: http://www.gwp.org/en/we-act/ themesprogrammes/Nexus-Water-Food-Energy-Ecosystems / (accessed on 12 February 2018).

14. UNECE. Reconciling Resource Uses in Transboundary Basins: Assessment of the Water-Food-Energy-Ecosystems Nexus. 2015. Available online: http:/ / www.unece.org/env/water/nexus.html (accessed on 12 February 2018).

15. Avellán, T.; Roidt, M.; Emmer, A.; von Koerber, J.; Schneider, P.; Raber, W. Making the Water-Soil-Waste Nexus Work: Framing the Boundaries of Resource Flows. Sustainability 2017, 9, 1881. [CrossRef]

16. Yu, Y.; Chen, D.; Hu, S.; Kharrazi, A.; Zhu, B. Advancing factors influencing resource productivity through the use of the material utility framework. J. Clean. Prod. 2017, 142, 1892-1900. [CrossRef]

17. Mohtar, R.H. A call for a new business model valuing water use and production: the Water, Energy and Food Nexus holistic system approach. Water Int. 2017, 42, 773-776. [CrossRef]

18. Rasul, G.; Sharma, B. The nexus approach to water-energy-food security: An option for adaptation to climate change. Clim. Policy 2015, 16, 682-702. [CrossRef]

19. IWMI. Catchment Water Allocation Tool (CaWAT). 2017. Available online: http://www.iwmi.cgiar.org/ resources/models-and-software/catchment-water-allocation-tool/ (accessed on 12 February 2018).

20. SEI. Water Evaluation and Planning. 2014. Available online: http:/ / www.weap21.org /index.asp?action=200 (accessed on 12 February 2018).

21. SEI. Long Range Energy Alternatives Planning System. 2013. Available online: http://sei-us.org/software/ leap (accessed on 12 February 2018).

22. FAO. CropWat. 2017. Available online: http://www.fao.org/land-water/databases-and-software/cropwat/ en/ (accessed on 12 February 2018).

23. KTH. CLEWs-Climate, Land, Energy and Water Strategies to Navigate the Nexus. 2013. Available online: https:/ / www.kth.se/en/forskning/forskningsplattformar/energy/news-events-video/events / empowering-analysts-to-navigate-the-clews-nexus-1.341928 (accessed on 28 December 2017).

24. Giampietro, M.; Aspinall, R.J.; Bukkens, S.G.F.; Benalcazar, J.C.; Diaz-Maurin, F.; Flammini, A.; Gomiero, T.; Kovacic, Z.; Madrid, C.; Ramos-Martín, J.; et al. An Innovative Accounting Framework for the Food-Energy-Water Nexus-Application of the MuSIASEM Approach to Three Case Studies; Environment and Natural Resources Working Paper No. 56; Food and Agriculture Organisation of the United Nations: Rome, Italy, 2013.

25. WEF Nexus Tool. Available online: http://wefnexustool.org/login.php (accessed on 9 January 2018).

26. FAO (United Nations Food and Agriculture Organization). The Water-Energy-Food Nexus a New Approach in Support of Food Security and Sustainable Agriculture. 2014. Available online: http:/ /www.fao.org/nr/ water/docs/FAOnexusconcept.pdf (accessed on 12 February 2018).

27. IRENA. Renewable Energy and the Water, Energy and Food Nexus. 2015. Available online: http:/ /www.irena.org/ documentdownloads/publications/irena_water_energy_food_nexus_2015.pdf (accessed on 12 February 2018).

28. Hardin, G. Commons 13. Science 1968, 162, 1243-1248. [CrossRef] [PubMed]

29. Hardin, R. Collective action as an agreeable n-prisoners' dilemma. Behav. Sci. 1971, 16. [CrossRef] 
30. Ostrom, E. Governing the Commons: The Evolution of Institutions for Collective Action; Cambridge University Press: Cambridge, UK, 1990.

31. Ostrom, E.; Burger, J.; Field, C.B.; Norgaad, R.B.; Policansky, D. Revisiting the Commons: Local Lessons, Global Challenges. Science 1999, 284, 278-282. [CrossRef] [PubMed]

32. Kurian, M.; Portney, K.E.; Rappold, G.; Hannibal, B.; Gebrechorkos, S.H. Governance of Water-Energy-Food Nexus: A Social Network Analysis Approach; Position Paper; Dresden Nexus Conference 2017; United Nations University: Dresden, Germany, 2017; Available online: https:/ / express2.converia.de/frontend/converia/ media/DNC_2017/Position_Papers/DNC2017_PP_Kurian_et_al_Governance_of_WEF_Nexus.pdf (accessed on 12 February 2018).

33. Lubell, M. Governing Forum Complexity: The Ecology of Games Framework. Policy Stud. J. 2013, 41, 537-559. [CrossRef]

34. Lubell, M.; Scholz, J.; Berardo, R.; Robins, G. Testing Policy Theory with Statistical Models of Networks. Policy Stud. J. 2012, 40, 351-374. [CrossRef]

35. Lubell, M.; Henry, A.D.; McCoy, M. Collaborative Institutions in an Ecology of Games. Am. J. Political Sci. 2010, 54, 287-300. [CrossRef]

36. Scott, C.A.; Kurian, M.; Wescoat, J.L., Jr. The Water-Energy-Food Nexus: Enhancing Adaptive Capacity to Complex Global Challenges. In Governing the Nexus: Water, Soil and Waste Resources Considering Global Change; Kurian, M., Ardakanian, R., Eds.; Springer: Cham, Switzerland, 2015.

37. Ostrom, E. A General Framework for Analyzing Sustainability of Social-Ecological Systems. Science 2009, 325, 419-422. [CrossRef] [PubMed]

38. Madrid, C.; Cabello, V.; Giampietro, M. Water-Use Sustainability in Socioecological Systems: A Multiscale Integrated Approach. BioScience 2013, 63, 14-24. [CrossRef]

39. Lussier, R.; Sherma, H. Business, Society, and Government Essentials: Strategy and Applied Ethics; Taylor and Francis: Oxford, UK, 2013.

40. Steiner, J.F.; Steiner, G.A. Business, Government and Society: A Managerial Perspective, Text and Cases-13th ed.; McGraw-Hill: New York, NY, USA, 2012; Available online: https:/ /www.homeworkmarket.com/ sites/default/files/qx/16/06/15/07/231074210-business-government-and-society-pdf_2_0.pdf (accessed on 12 February 2018).

41. Doppelt, B. Leading Change Toward Sustainability: A Change-Management Guide for Business, Government, and Civil Society; Greenleaf Publishing Limited: Oxford, UK, 2010.

42. Dentchev, N.A.; Haezendonck, E.; van Balen, M. The Role of Governments in the Business and Society Debate. Sage J. 2015. [CrossRef]

43. Aßländer, M.; Curbach, J. Corporate or governmental duties? Corporate citizenship from a governmental perspective. Bus. Soc. 2017, 56, 617-645. [CrossRef]

44. Dahan, N.M.; Doh, J.P.; Raelin, J.D. Pivoting the Role of Government in the Business and Society Interface: A Stakeholder Perspective. J. Bus. Ethics 2014, 131, 665-680. [CrossRef]

45. Newborne, P.; Dalton, J. Water Management and Stewardship: Taking Stock of Corporate Water Behavior; IUCN: Gland, Switzerland; London, UK, 2016; Available online: https:/ / portals.iucn.org/library/sites/library/ files/documents /2016-069.pdf (accessed on 12 February 2018).

46. Gallagher, L.; Dalton, J.; Bre'thaut, C.; Allan, T.; Bellfield, H.; Crilly, D.; Cross, K.; Gyawali, D.; Klein, D.; LeFlaive, S.; et al. The critical role of risk in setting directions for water, food and energy policy and research. Curr. Opin. Environ. Sustain. 2016, 23, 12-16. [CrossRef]

47. United Nations. Sustainable Development Goals. 2015. Available online: https://sustainabledevelopment. un.org/?menu=1300 (accessed on 12 February 2018).

48. International Council for Science. A Guide to SDG Interactions: From Science to Implementation. 2017. Available online: https://www.icsu.org/publications/a-guide-to-sdg-interactions-from-scienceto-implementation (accessed on 12 February 2018).

(C) 2018 by the authors. Licensee MDPI, Basel, Switzerland. This article is an open access article distributed under the terms and conditions of the Creative Commons Attribution (CC BY) license (http:/ / creativecommons.org/licenses/by/4.0/). 